\title{
RNA Transport
}

National Cancer Institute

\section{Source}

National Cancer Institute. RNA Transport. NCI Thesaurus. Code C18127.

RNA transport is the translocation of RNA molecules from one cellular location to another, such as transport from the nucleus to the cytoplasm. 